\title{
Arterial dissection in childhood Takayasu Arteritis: not as rare as thought
}

\author{
Florence A. Aeschlimann'1, Lars Grosse-Wortmann², Susanne M. Benseler ${ }^{3}$, Ronald M. Laxer ${ }^{1}$, Diane Hebert ${ }^{4}$ \\ and Rae S.M. Yeung ${ }^{1,5^{*}}$
}

\begin{abstract}
Background: Arterial vessel wall dissection is a rare, life-threatening and rarely described complication in childhood Takayasu Arteritis (CTA). Prevalence and risk factors for arterial dissection in CTA are unknown. We sought to study the prevalence and analyse risk factors for arterial dissection in CTA.

Findings: A single center retrospective review of all children with cTA was performed. Patients with arterial dissection at CTA diagnosis were reported in detail and compared to the remaining single center retrospective cohort of children without dissection. Disease activity was assessed by the Pediatric Vasculitis Disease Activity Score (PVAS). A total of 27 CTA patients (74 \% girls) were included. Three children (11\%) presented with dissection at diagnosis of cTA. They had higher PVAS (median 21 versus 10, $p=0.26)$, increased neutrophils $(p<0.0001)$ and lower albumin levels $(p=0.05)$. Arterial hypertension was common in both groups: in $67 \%$ of children with dissection and $54 \%$ of those without.

Conclusions: Arterial dissection was more frequent in our CTA cohort than previously reported. Careful vascular imaging assessment is crucial to document this complication. High disease activity and markers of inflammation especially in combination with arterial hypertension, may be associated with the risk for vessel wall dissection in children with CTA.
\end{abstract}

Keywords: Takayasu arteritis, Vasculitis, Children, Imaging, Arterial dissection

\section{Background}

Childhood Takayasu Arteritis (cTA) is a devastating vasculitis characterised by granulomatous inflammation of the aorta and its major branches resulting in severe ischemic organ dysfunction [1]. Arterial dissection is a rare, lifethreatening complication [2]. The prevalence of and risk factors for dissection in cTA are unknown. Therefore, the aims of this study were to: 1) determine the prevalence of dissection in cTA; 2) compare clinical, laboratory and imaging characteristics of cTA with and without dissection and 3) identify risk factors for dissection in cTA.

\footnotetext{
* Correspondence: rae.yeung@sickkids.ca

'Division of Rheumatology, Department of Paediatrics, The Hospital for Sick Children, University of Toronto, Toronto, ON, Canada

${ }^{5}$ Department of Immunology and Institute of Medical Science, University of Toronto, Toronto, ON, Canada

Full list of author information is available at the end of the article
}

\section{Findings}

\section{Hypothesis}

Childhood TA patients with dissection have higher disease activity compared to cTA patients without dissection.

\section{Methods}

This single, tertiary care center study included all consecutive children diagnosed with cTA and meeting the EULAR/PRINTO/PReS classification criteria between 1986 and 2015 [3]. Before 2009, all children were diagnosed based on the American College of Rheumatology criteria and also met the EULAR/PRINTO/PReS classification criteria for cTA $[4,5]$. Children were identified from the institutional databases; data were captured using standardized forms under an Institutional Research Ethics Board approved study which waived the requirement for informed consent.

Demographic, clinical, laboratory and imaging data at presentation were captured. Disease activity was determined using the validated Pediatric Vasculitis Activity Score (PVAS) [6]. Arterial dissection was defined as presence of a 
double lumen with visible intimal flap and/or an intramural hematoma on vascular imaging [7]. Magnetic resonance imaging with angiography (MRI/A) has become the first line imaging modality in CTA in our institution due to its reduced exposure to ionizing radiation and its non-invasive procedure when compared to conventional angiography. All images were reviewed by an expert reader in cardiovascular imaging with more than 10 years experience (LGW) in addition to standard clinical review as part of patient management. Groups were compared using parametric and non-parametric tests as appropriate; analyses were conducted in Prism (GraphPad 6.0 g, San Diego).

\section{Results}

A total of 27 cTA patients ( $74 \%$ female) were included. Median age at diagnosis was 12.4 years (range 4.2-17.7). Spontaneous dissection was found in $3 / 27$ children (11\%). Dissections were seen in the abdominal aorta in two and in the carotid artery in one child. No additional dissections were detected during the follow-up period. The three children and their vascular findings are described below, and detailed in Table 1 and Fig. 1 .

\section{Patient 1}

A 14-year-old girl was referred with a two-month history of constitutional symptoms. She presented with acute hypertensive crisis and cardiovascular decompensation. She had weak femoral pulses and blood pressure discrepancy between limbs. MRI/A was consistent with cTA and revealed a large dissection flap in the abdominal aorta (Fig. 1a). Quadruple antihypertensive treatment and pulse methylprednisolone were started. While attempting to lower the blood pressure, the renal perfusion deteriorated resulting in renal failure. An emergent axillary-femoral artery bypass conduit was placed to provide retrograde renal perfusion resulting in rapid improvement of renal function and blood pressure control. The aortic aneurysm and the dissection flap were left unchanged. Subsequently, methotrexate and infliximab were started and prednisone was tapered. She achieved remission at six months of therapy and continued to be in remission on medication including methotrexate, infliximab and low-dose prednisone at 26 months of follow-up. Repeat MRI/As showed no evidence of new vascular lesions or ongoing vessel inflammation. While the dissection flap remained unchanged during initial follow-up imaging, the last MRI/A at 26 months of follow-up showed a spontaneous reposition of the dissection flap along the aortic wall.

\section{Patient 2}

A 12-year-old girl presented at a local hospital with constitutional symptoms and bilateral cervical lymphadenopathy. She was normotensive, but had decreased left radial and pedal pulses. Lymph node biopsy showed active extrapulmonary tuberculosis (diagnosis confirmed by positive culture); clinically and radiologically there was no evidence of tuberculosis infection in the lung or any other anatomical site. Quadruple anti-tuberculosis treatment was started. MRI/A demonstrated extensive aortitis with a dissection in the abdominal aorta (Fig. 1b). Following diagnosis of cTA high-dose prednisone was initiated. Due to active vessel wall inflammation surgical intervention was not considered a therapeutic option. Repeat imaging at six months revealed radiographic progression, despite a clinically stable course. Azathioprine was added, but inflammatory markers increased further. Azathioprine was switched to mycophenolate mofetil due to persistent leucopenia. She was referred for second opinion two years after diagnosis. Investigations revealed increased inflammatory markers. MRI/A showed vessel wall thickening and persistent aortic dissection. There was no evidence of ongoing tuberculosis infection. Treatment modifications including increased prednisone were suggested. She discontinued the treatment three years after diagnosis against medical advice. Regular follow-up MRI/As were performed, the last one, 6 years after diagnosis, did not show evidence of active disease or dissection; clinically she was asymptomatic.

\section{Patient 3}

A 10-year-old girl presented with three episodes of focal seizures with secondary generalization. She had a threemonth history of constitutional symptoms. Clinical examination revealed severe hypertension, midline abdominal bruits and a right cervical pulsatile mass. Brain MR was consistent with posterior reversible encephalopathy secondary to arterial hypertension. MRI/A findings were consistent with cTA, an intramural hematoma with suspected dissection flap was seen in the right carotid artery (Fig. 1c and 1d). She was started on high-dose prednisone, methotrexate and quintuple antihypertensive treatment. The intramural hematoma with suspected dissection flap was managed with conventional treatment, as active vessel wall inflammation precluded a surgical intervention. While tapering prednisone, inflammatory markers increased. Repeat MRI/A at eight months revealed new aortic lesions and an increasing carotid aneurysm. Tocilizumab was added. At 36-month follow-up, she continued to be asymptomatic with normal inflammatory markers while treated with tocilizumab, methotrexate and low-dose prednisone. Repeat MRI/A revealed no evidence of active disease; the right carotid artery hematoma had resolved; a dissection flap was not detected. The carotid artery aneurysm remained unchanged.

In all three patients with dissection, potential other causes of arterial dissection such as syphilis and HIV were excluded serologically. All children were tested for tuberculosis infection at diagnosis of cTA. One child in 
Table 1 Characteristic features of the patients with cTA and dissection

\begin{tabular}{|c|c|c|c|}
\hline & Patient 1 & Patient 2 & Patient 3 \\
\hline Age at diagnosis & 14.6 years & 12.4 years & 10.3 years \\
\hline Age at symptom onset & 14.4 years & $?$ & 10.0 years \\
\hline Gender & Female & Female & Female \\
\hline Ethnicity & First Nations & African & East Indian \\
\hline Presenting symptoms & $\begin{array}{l}\text { Constitutional symptoms, abdominal pain, } \\
\text { headache, cough, chest pain, dyspnea }\end{array}$ & $\begin{array}{l}\text { Constitutional symptoms, bilateral cervical } \\
\text { lymphadenopathy }\end{array}$ & $\begin{array}{l}\text { Constitutional symptoms, vomiting, left focal } \\
\text { seizures with secondary generalization }\end{array}$ \\
\hline Clinical findings & $\begin{array}{l}\text { Arterial hypertension, weak femoral and } \\
\text { pedal pulses, BP discrepancy of } 50 \mathrm{mmHg} \text {, } \\
\text { cardio-respiratory failure }\end{array}$ & $\begin{array}{l}\text { Decreased left radial and peripheral pedal } \\
\text { pulses }\end{array}$ & $\begin{array}{l}\text { Arterial hypertension, midline abdominal bruits, } \\
\text { BP discrepancy, pulsatile right cervical mass }\end{array}$ \\
\hline Laboratory findings & $\begin{array}{l}\text { WBC } 13.6 \times 10^{9} / \mathrm{L} \\
\text { Neutrophils } 12.3 \times 10^{9} / \mathrm{L} \\
\text { Hb } 83 \mathrm{~g} / \mathrm{l} \\
\text { ESR } 31 \mathrm{~mm} / \mathrm{h} \\
\text { CRP } 14.5 \mathrm{mg} / \mathrm{dL} \\
\text { Albumin } 25 \mathrm{~g} / \mathrm{L} \\
\text { Creatinine } 123 \mathrm{umol} / /\end{array}$ & $\begin{array}{l}\text { WBC } 5.17 \times 10^{9} / \mathrm{L} \\
\text { Neutrophils not done } \\
\text { Hb } 144 \mathrm{~g} / \mathrm{l} \\
\text { ESR } 32 \mathrm{~mm} / \mathrm{h} \\
\text { CRP not done } \\
\text { Albumin } 36 \mathrm{~g} / \mathrm{L}\end{array}$ & $\begin{array}{l}\text { WBC } 22.3 \times 10^{9} / \mathrm{L} \\
\text { Neutrophils } 19.1 \times 10^{9} / \mathrm{L} \\
\text { Hb } 115 \mathrm{~g} / \mathrm{l} \\
\text { ESR } 40 \mathrm{~mm} / \mathrm{h} \\
\text { CRP } 24.2 \mathrm{mg} / \mathrm{dL} \\
\text { Albumin } 36 \mathrm{~g} / \mathrm{L}\end{array}$ \\
\hline Radiological findings & $\begin{array}{l}\text { CTA and MRI/A: } \\
\text { Thickening of entire abdominal aorta with } \\
\text { dilatation and post-contrast enhancement } \\
\text { of the wall. } \\
\text { Dissection of the abdominal aorta with } \\
\text { intramural hematoma. } \\
\text { Severe narrowing of SMA, celiac artery and } \\
\text { both renal arteries. }\end{array}$ & $\begin{array}{l}\text { MRI/A: } \\
\text { Extensive arteritis involving aortic arch, entire } \\
\text { descending aorta and upper abdominal aorta } \\
\text { with lumen irregularity, vessel wall thickening } \\
\text { and post-contrast enhancement. Descending } \\
\text { aorta with two areas of dilatation, in between } \\
\text { narrowing with evidence of dissection. } L \\
\text { subclavian artery severely narrowed. }\end{array}$ & $\begin{array}{l}\text { MRI/A: } \\
\text { Thickening and post-contrast enhancement of } \\
\text { the abdominal aorta with evidence of an } \\
\text { aneurysm. R carotid artery aneurysm with } \\
\text { perivascular edema and vessel inflammation, } \\
\text { intramural hematoma and suspected dissection } \\
\text { flap. Bilateral renal artery stenosis; dilatation of } \\
\text { the origin of the celiac trunk and SMA. }\end{array}$ \\
\hline PVAS (max. score 63) & 21 & 8 & 25 \\
\hline \multirow[t]{2}{*}{ Treatment } & $\begin{array}{l}\text { Induction: } \\
\text { Pulse Methylprednisolone, then high-dose } \\
\text { Prednisone Methotrexate orally } \\
\text { Infliximab every } 4 \text { weeks }\end{array}$ & $\begin{array}{l}\text { Induction: } \\
\text { High dose Prednisone }\end{array}$ & $\begin{array}{l}\text { Induction: } \\
\text { High-dose Prednisone Methotrexate subcutaneously }\end{array}$ \\
\hline & $\begin{array}{l}\text { Other: } \\
\text { Quadruple anti-hypertensive therapy } \\
\text { ASA }\end{array}$ & $\begin{array}{l}\text { Other: } \\
\text { Anti-tuberculosis therapy }\end{array}$ & $\begin{array}{l}\text { Other: } \\
\text { Quintuple anti-hypertensive therapy } \\
\text { ASA }\end{array}$ \\
\hline Follow-up duration & 26 months & 6 years & 36 months \\
\hline
\end{tabular}



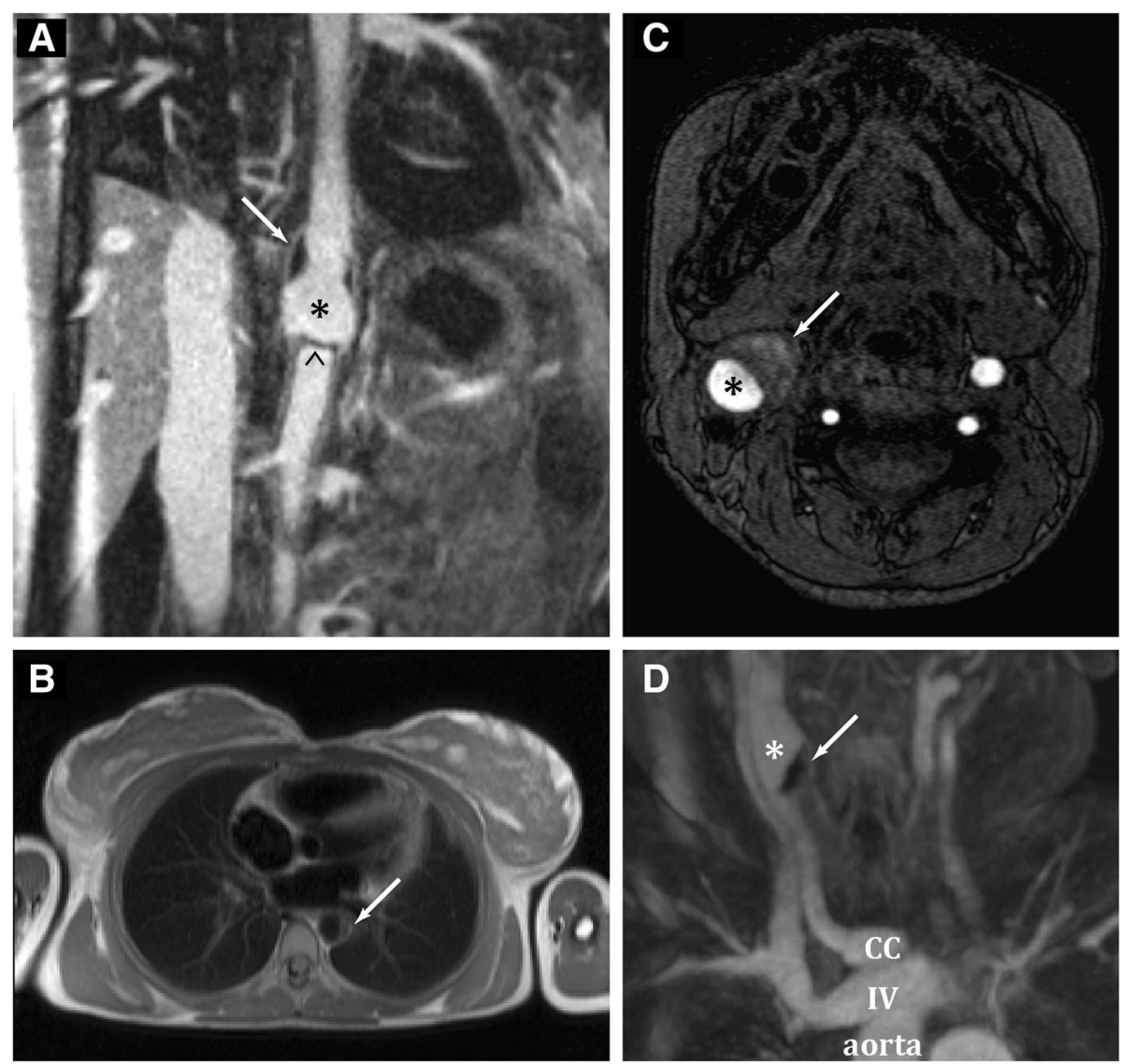

Fig. 1 Vascular imaging in the three children with Takayasu arteritis and dissection. Legend: Patient 1: a A coronal reformat of the 3D volume rendered MRA dataset demonstrates the intramural hematoma (arrow) as well as a dissection flap (arrowhead) at the caudal end of the aneurysm $\left(^{*}\right)$ in the abdominal aorta. The intramural hematoma (arrow) is located at the proximal end of the aneurysm. The celiac axis arises immediately distal to the dissection flap with a stenotic origin. There is thickening of the aortic wall and a long-segment narrowing of the infra-renal aorta. Patient 2: b A T2 weighted turbo spin echo magnetic resonance image in the axial orientation shows a dissection flap in the thoracic descending aorta at the level of the left atrium (arrow). Patient 3: c The T1 weighted turbo spin echo and $\mathbf{d}$ the para-coronal reformat of a contrast-enhanced magnetic resonance angiogram show an aneurysm of the right carotid artery $\left(^{*}\right)$ with intramural hematoma (arrow). CC $=C$ Common carotid artery, $\mathbf{I V}=$ innominate vein

the dissection group $(1 / 3,33 \%)$ and 2 children in the non-dissection group $(2 / 24,8 \%)$ were diagnosed with tuberculosis infection. Patients with dissection $(N=3)$ and those without $(N=24)$ are detailed in Table 2. At diagnosis, there was no statistically significant difference in gender, age, presence of specific clinical symptoms or tuberculosis infection when comparing cTA patients with dissection and those without. Hypertension was common, with $67 \%$ being hypertensive in the dissection group compared to $54 \%$ in the non-dissection group $(p=1)$. Overall, children with dissection had a trend towards higher disease activity at diagnosis as measured by median PVAS (21 versus 10 ), but this was not statistically significant $(p=0.26)$. They had significantly higher neutrophil counts (mean $15.7 \times 10^{9} / \mathrm{L}$ versus $5.8 \times 10^{9} / \mathrm{L}, \quad p<0.0001$ ) and lower albumin levels (mean $32.3 \mathrm{~g} / \mathrm{l}$ versus $41.1 \mathrm{~g} / \mathrm{l}$, $p=0.05$ ). There was no statistically significant difference seen in ESR, hemoglobin, platelets, creatinine and von Willebrand factor antigen levels.

\section{Discussion}

This is the first study to determine the prevalence of dissections in cTA; one in 10 children with cTA $(3 / 27$, $11 \%)$, had evidence of dissection on initial imaging. To date, only one case report of dissection in a child with cTA has been published [2]. Interestingly, large cTA cohorts have not reported dissection at diagnosis, including those providing detailed description of vessel wall disease [8-12]. Overall, improved vessel wall imaging techniques have resulted in more detailed characterization of the vascular structure [13]. Dissection has important implications for therapeutic decisions, especially involving anti-coagulation and anti-platelet agents. In the presence 
Table 2 Demographics, clinical and laboratory features in cTA patients with and without dissection

\begin{tabular}{|c|c|c|c|}
\hline & $\begin{array}{l}\text { CTA with dissection } \\
(\mathrm{N}=3)\end{array}$ & $\begin{array}{l}\text { CTA without dissection } \\
(\mathrm{N}=24)\end{array}$ & $P$-value \\
\hline Age at diagnosis in years, mean (SD) & $12.4(2.2)$ & $11.5(3.7)$ & 0.37 \\
\hline Female (\%) & $3(100)$ & $17(71)$ & 0.55 \\
\hline Tuberculosis (\%) & $1(33)$ & $2(8)$ & 0.29 \\
\hline Arterial hypertension (\%) & $2(66)$ & $13(54)$ & 1 \\
\hline Constitutional symptoms (\%) & $3(100)$ & $14(58)$ & 0.27 \\
\hline PVAS, median (IQR) & $21(8-25)$ & $10(6-35)$ & 0.26 \\
\hline ESR in $\mathrm{mm} / \mathrm{h}$, median (IQR) & $32(31-40)$ & $35(1-109)$ & 0.89 \\
\hline Albumin in $\mathrm{g} / \mathrm{L}$, mean (SD) & $32.3(6.4)$ & $41.1(6.6)$ & 0.05 \\
\hline Hemoglobin in $\mathrm{g} / \mathrm{L}$, mean (SD) & $113.7(31.0)$ & $112.8(18.4)$ & 0.95 \\
\hline WBC in $\times 10^{9}$, mean (SD) & $13.7(8.6)$ & $9.3(3.0)$ & 0.07 \\
\hline Neutrophils in $\times 10^{9}$, mean (SD) & $15.7(4.8)$ & $5.8(2.3)$ & $<0.0001$ \\
\hline Platelets in $\times 10^{9}$, mean (SD) & $349(183)$ & $401(155)$ & 0.60 \\
\hline \multicolumn{4}{|l|}{ Imaging at diagnosis (\%) } \\
\hline MRI/A & $3(100)$ & $5(21)$ & 0.02 \\
\hline Conventional angiography & 0 & $6(25)$ & 1 \\
\hline Combined (MRI/A, CTA, angiography) & 0 & $13(54)$ & 0.22 \\
\hline
\end{tabular}

Legend: Data are presented as counts with percentages, mean with standard deviation (SD) or median with interquartile range (IQR). Constitutional symptoms included malaise, weight loss, fever and lymphadenopathy. C-reactive protein was not included into the analysis, as the assay method changed during the study period

PVAS pediatric vasculitis activity score, ESR erythrocyte sedimentation rate, WBC white blood cell count, MRI/A magnetic resonance imaging with angiography, CTA computer tomography angiography

of an intramural hematoma anti-coagulation should be avoided due to increased bleeding risk.

This study analysed possible risk factors for dissections in cTA. Children with dissection tended to present with evidence of high disease activity including high PVAS, increased neutrophils and lower albumin levels. Disease activity and inflammation in Takayasu Arteritis (TA) is thought to be mediated through activated monocytes, macrophages and T-cells that synthetize pro-inflammatory cytokines, including TNF-alpha and IL-6 [14]. These cytokines in particular mediate production of matrix metalloproteases (MMPs), a family of proteolytic enzymes able to destroy components of the extracellular matrix - the scaffolding holding the vessel wall components together. In adults with TA, higher levels of MMPs, especially MMP-9, and lower levels of MMP inhibitors correlate with disease activity [15, 16]. Further, distinct MMP subtypes have been associated with aneurysms and dissection in other vascular diseases including Kawasaki disease and type A acute aortic dissection $[17,18]$. In general, children present with hyperacute inflammation at diagnosis of TA, which was also seen in our patient population. This may put them at higher risk for dissection, despite a lack of statistical difference in surrogate measures of inflammation in our very small cohort. Interestingly, one child presented with concomitant Mycobacterium tuberculosis infection. In tuberculosis, intercellular networks including TNF-alpha also drive increased MMP gene expression and secretion [19].
Even though the presence of arterial hypertension was not statistically significantly different in the dissection group, it may play an important role in the development of dissection. Hypertension-related rupture of the vasa vasorum with subsequent development of an intramural hematoma has been suggested as possible pathomechanism for dissection in acute aortic syndromes in adults [20]. The vasa vasorum feed the media layer of vessels and their rupture may lead to creation of an intramural hematoma with or without intimal tear [20]. This mechanism is even more deleterious in vessels with wall inflammation and potential distal stenosis as demonstrated in our first patient. This may create critical pressure in a weakened vessel wall and subsequently increases the risk for dissection.

There are several limitations to the study. This is a retrospective study spanning three decades and different therapeutic management regimens. The cohort was followed at a single tertiary care center, which may result in inclusion of sicker children and overestimation of the prevalence of dissections. In contrast, vascular imaging techniques have dramatically improved, which may have led to underestimation of dissections in those diagnosed earlier. The patient numbers are small and results may not be representative, but nonetheless, highlight the importance of this complication, as dissection has important implications for therapeutic decisions, especially involving anti-coagulation and anti-platelet 
agents. Further studies are necessary to confirm our preliminary data.

\section{Conclusion}

Dissection in cTA appears to be more frequent than previously appreciated. Careful vessel wall assessment with high quality vascular imaging is therefore required in these patients. In this study, statistically significant difference between children with dissection and those without dissection was not found, most likely due to the small sample size. Nonetheless, high disease activity and inflammation especially in combination with hypertension, may increase the risk for development of dissection in children with TA. Recognition and identification of these risk factors are important in the management of cTA.

\section{Abbreviations}

ASA: Acetylsalicylic acid; BP discrepancy: Blood pressure discrepancy; CC: Common carotid artery; CRP: C-reactive protein; CTA: Childhood Takayasu Arteritis; CTA: Computer tomography angiography; ESR: Erythrocyte sedimentation rate; EULAR/PRINTO/PReS: European League against Rheumatism (EULAR)/Pediatric Rheumatology International Trials Organization (PRINTO)/Pediatric Rheumatology European Society (PReS); $\mathrm{Hb}$ : Hemoglobin; IV: Innominate vein; MMP: Matrix metalloprotease; MRI/A: Magnetic resonance imaging/angiography; PVAS: Pediatric vasculitis activity score; SMA: Superior mesenteric artery; WBC: White blood cell count

\section{Acknowledgement}

We thank Suzanne Tam for the valuable technical support.

\section{Funding}

FAA is supported by the Rhyner-Bangerter Foundation, Starr-Foundation, Swiss League against Rheumatism, Foundation W!, Alberta Children's Hospital Research Institute Foundation, Dawson Jarock Foundation and SickKids Foundation. RSMY is supported by the Hak-Ming and Deborah Chiu Chair in Paediatric Translational Research at The Hospital For Sick Children, University of Toronto.

\section{Availability of data and material}

All data and materials related to this study are available and presented in the manuscript and accompanying tables and figures.

\section{Authors' contributions}

All authors were involved in drafting the article or revising it critically for important intellectual content. All authors have approved the final version to be published. Study conception and design: FAA, RSMY. Acquisition of data: FAA, LGW, SMB, RML, DH, RSMY. Analysis and interpretation of data: FAA, LGW, SMB, RSMY.

\section{Competing interests}

The authors declare that they have no competing interests.

\section{Consent for publication}

Not applicable (see above).

\section{Ethics approval and consent to participate}

This study was approved by the Research Ethics Board at The Hospital For Sick Children, Toronto, Ontario, Canada, which waived the requirement for informed consent (Study No. 1000012364).

\section{Author details}

${ }^{1}$ Division of Rheumatology, Department of Paediatrics, The Hospital for Sick Children, University of Toronto, Toronto, ON, Canada. '2Division of Cardiology, Department of Paediatrics, The Hospital for Sick Children, University of Toronto, Toronto, ON, Canada. ${ }^{3}$ Rheumatology, Department of Paediatrics, Alberta Children's Hospital, University of Calgary, Calgary, AB, Canada. ${ }^{4}$ Division of Nephrology, Department of Paediatrics, The Hospital for Sick
Children, University of Toronto, Toronto, ON, Canada. ${ }^{5}$ Department of Immunology and Institute of Medical Science, University of Toronto, Toronto, ON, Canada.

Received: 9 July 2016 Accepted: 15 September 2016

Published online: 22 September 2016

\section{References}

1. Brunner J, Feldman BM, Tyrrell PN, Kuemmerle-Deschner JB, Zimmerhackl LB, Gassner l, et al. Takayasu arteritis in children and adolescents. Rheumatology (Oxford). 2010:49(10):1806-14.

2. Civilibal M, Sever L, Numan F, Altun G, Ocak S, Candan C, et al. Dissection of the abdominal aorta in a child with Takayasu's arteritis. Acta Radiol. 2008;49(1):101-4.

3. Ozen S, Pistorio A, lusan SM, Bakkaloglu A, Herlin T, Brik R, et al. EULAR/ PRINTO/PRES criteria for Henoch-Schonlein purpura, childhood polyarteritis nodosa, childhood Wegener granulomatosis and childhood Takayasu arteritis: Ankara 2008. Part II: Final classification criteria. Ann Rheum Dis. 2010;69(5):798-806.

4. Bloch DA, Michel BA, Hunder GG, MCShane DJ, Arend WP, Calabrese LH, et al. The American College of Rheumatology 1990 criteria for the classification of vasculitis. Patients and methods. Arthritis Rheum. 1990;33(8):1068-73.

5. Hunder GG, Arend WP, Bloch DA, Calabrese LH, Fauci AS, Fries JF, et al. The American College of Rheumatology 1990 criteria for the classification of vasculitis. Introduction. Arthritis Rheum. 1990;33(8):1065-7.

6. Dolezalova P, Price-Kuehne FE, Ozen S, Benseler SM, Cabral DA, Anton J, et al. Disease activity assessment in childhood vasculitis: development and preliminary validation of the Paediatric Vasculitis Activity Score (PVAS). Ann Rheum Dis. 2013;72(10):1628-33.

7. Svensson LG, Labib SB, Eisenhauer AC, Butterly JR. Intimal tear without hematoma: an important variant of aortic dissection that can elude current imaging techniques. Circulation. 1999;99(10):1331-6.

8. Goel R, Kumar TS, Danda D, Joseph G, Jeyaseelan V, Surin AK, et al. Childhood-onset Takayasu arteritis - experience from a tertiary care center in South India. J Rheumatol. 2014;41(6):1183-9.

9. Hahn D, Thomson PD, Kala U, Beale PG, Levin SE. A review of Takayasu's arteritis in children in Gauteng, South Africa. Pediatr Nephrol. 1998;12(8):668-75.

10. Eleftheriou D, Varnier G, Dolezalova P, McMahon AM, Al-Obaidi M, Brogan PA. Takayasu arteritis in childhood: retrospective experience from a tertiary referral centre in the United Kingdom. Arthritis Res Ther. 2015;17:36.

11. Szugye HS, Zeft AS, Spalding SJ. Takayasu Arteritis in the pediatric population: a contemporary United States-Based Single Center Cohort. Pediatr Rheumatol Online J. 2014;12:21.

12. Cakar N, Yalcinkaya F, Duzova A, Caliskan S, Sirin A, Oner A, et al. Takayasu arteritis in children. J Rheumatol. 2008;35(5):913-9.

13. Hartlage GR, Palios J, Barron BJ, Stillman AE, Bossone E, Clements SD, et al. Multimodality imaging of aortitis. JACC Cardiovasc Imaging. 2014;7(6):605-19.

14. Arnaud L, Haroche J, Mathian A, Gorochov G, Amoura Z. Pathogenesis of Takayasu's arteritis: a 2011 update. Autoimmun Rev. 2011;11(1):61-7.

15. Matsuyama A, Sakai N, Ishigami M, Hiraoka H, Kashine S, Hirata A, et al. Matrix metalloproteinases as novel disease markers in Takayasu arteritis. Circulation. 2003;108(12):1469-73.

16. Ishihara T, Haraguchi G, Tezuka D, Kamiishi T, Inagaki H, Isobe M. Diagnosis and assessment of Takayasu arteritis by multiple biomarkers. Circ J. 2013;77(2):477-83.

17. Lau AC, Duong TT, Ito S, Yeung RS. Matrix metalloproteinase 9 activity leads to elastin breakdown in an animal model of Kawasaki disease. Arthritis Rheum. 2008;58(3):854-63

18. Manabe T, Imoto K, Uchida K, Doi C, Takanashi Y. Decreased tissue inhibitor of metalloproteinase-2/matrix metalloproteinase ratio in the acute phase of aortic dissection. Surg Today. 2004:34(3):220-5.

19. Elkington PT, Ugarte-Gil CA, Friedland JS. Matrix metalloproteinases in tuberculosis. Eur Respir J. 2011;38(2):456-64.

20. Macura KJ, Corl FM, Fishman EK, Bluemke DA. Pathogenesis in acute aortic syndromes: aortic dissection, intramural hematoma, and penetrating atherosclerotic aortic ulcer. AJR Am J Roentgenol. 2003;181(2):309-16. 